\title{
Erratum to: Recent observations on site reactions in cattle to vaccination against contagious bovine pleuropneumonia (CBPP) using T1/44 vaccine in Zambia
}

Geoffrey Munkombwe Muuka • Webster Chikampa •

Cornelius Mundia • Domenico Buonavoglia • Atilio Pini •

Massimo Scacchia

Published online: 25 January 2014

(C) Springer Science+Business Media Dordrecht 2014

Erratum to: Trop Anim Health Prod

DOI 10.1007/s11250-013-0429-9

There was an error in the author's name of the article

The correct name is:

D. Buonavoglia

The online version of the original article can be found at http:// dx.doi.org/10.1007/s11250-013-0429-9.

G. M. Muuka $(\bowtie) \cdot$ W. Chikampa $\cdot$ C. Mundia

Ministry of Agriculture and Livestock, Lusaka, Zambia

e-mail: geoffreymuuka@yahoo.co.uk

G. M. Muuka • D. Buonavoglia

School of Animal Health Sciences and Zoonosis,

University of Bari, Bari, Italy

A. Pini $\cdot$ M. Scacchia

Istituto Zooprofilactico Sperimentale "G. Caporale", Teramo, Italy 